\title{
POPULATION STUDY ARTICLE OPEN Persistent organic pollutants in pregnant women potentially affect child development and thyroid hormone status
}

\author{
Anna A. Krönke ${ }^{1}$, Anne Jurkutat ${ }^{2}$, Maike Schlingmann ${ }^{1}$, Tanja Poulain ${ }^{2}$, Matthias Nüchter ${ }^{2}$, Anja Hilbert ${ }^{3,4}$, Hannu Kiviranta ${ }^{5}$,
} Antje Körner ${ }^{1,2,3}$, Mandy Vogel ${ }^{1,2}$, Olle Söder ${ }^{6}$, Carl G. Bornehag ${ }^{7,8}$ and Wieland Kiess ${ }^{1,2}$

BACKGROUND: Potentially harmful effects of persistent organic pollutants (POPs) such as polychlorinated biphenyls (PCBs) and dichlorodiphenyltrichloroethane (DDT) on prenatal development and the endocrine system have been controversially discussed. METHODS: Working with a German cohort of 324 pregnant women, we assessed POP levels and used robust linear regression models to determine potential associations between maternal POP concentrations and pre- and postnatal development in the children, as well as the thyroid hormone status of the mother and child.

RESULTS: Maternal $p, p^{\prime}$-dichlorodiphenyldichloroethylene $\left(p, p^{\prime}\right.$-DDE) and most measured PCBs positively correlated with postnatal weight gain. We detected no correlation between newborn birth weight and head circumference, respectively, and maternal PCB and $p, p^{\prime}$-DDE serum levels, while body length at birth was negatively associated with the maternal serum concentration of PCB 183 . Maternal $p, p^{\prime}$-DDE and nearly all PCB serum levels showed a negative correlation with maternal free triiodothyronine (FT3). $p, p^{\prime}$-DDE and PCB 74 and 118 were negatively associated with maternal thyroid-stimulating hormone levels. In addition, we identified significant associations between maternal POP levels and thyroid hormone parameters of the child.

CONCLUSIONS: These results indicate that POP exposure likely affects different aspects of pre- and postnatal development and impacts the thyroid hormone status of both mother and child.

Pediatric Research (2022) 91:690-698; https://doi.org/10.1038/s41390-021-01488-5

\section{IMPACT:}

- Pregnant women in a German cohort display a substantial accumulation of POPs.

- Body mass index and age influence maternal serum POP levels.

- Maternal POP levels show correlations with the child's length at birth and weight gain, and FT3 levels in the mother and child.

- Our data provide additional evidence for the potentially harmful influence of POPs.

- Our data indicate that POPs influence pre- and postnatal development.

\section{INTRODUCTION}

Polychlorinated biphenyls (PCBs) exhibit varying degrees of halogenation, ranging from one to ten chlorine atoms. As the number of chlorine atoms increases, so does the environmental persistence of the PCB in question. ${ }^{1}$ Due to their chemical properties, PCBs were widely used as coolant and dielectric fluids, in capacitors and as a joint sealing material. ${ }^{2}$ The parties of the Stockholm convention largely banned the production and use of $\mathrm{PCBs}$, along with that of other persistent organic pollutants (POPs) such as the insecticide dichlorodiphenyltrichloroethane (DDT), but an equipment that contains or is contaminated by PCBs may be used until 2025. ${ }^{3}$

Although the implementation of such prohibitive measures has led to a decrease in their environmental concentrations, these pollutants can still be detected in organisms worldwide. The reason for the persistence of these substances is their resistance to environmental degradation and high lipophilicity, which leads to accumulation both in the food chain and in human tissues. Importantly, there is increasing evidence that they still act as an endocrine-modulating substance, even at low levels that were initially considered safe. ${ }^{4}$ The results of several animal experiments and a number of epidemiological studies suggest that the prenatal phase and childhood are especially vulnerable to the influence of endocrine modulators of this sort. ${ }^{5}$ It is for this reason that-in the publication "State of the science of endocrine disrupting chemicals -2012" - the World Health Organization recommended focusing further investigations on the impact of these compounds on human prenatal development. ${ }^{5}$ There is evidence that prenatal exposure to certain PCBs and to $p, p^{\prime}$-DDT and its main degradation product, $p, p^{\prime}$ dichlorodiphenyldichloroethylene $\left(p, p^{\prime}\right.$-DDE), can have adverse effects on growth and metabolism, and on neurocognitive development, sexual development and reproduction. ${ }^{6}$

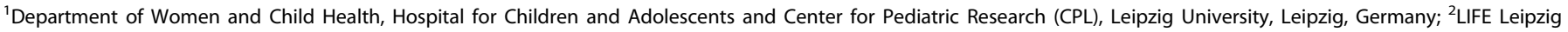

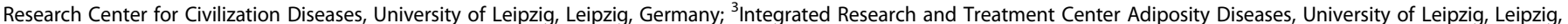

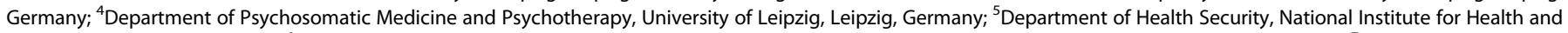

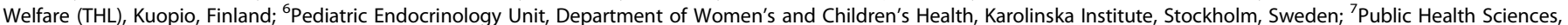
Karlstad University, Karlstad, Sweden and ${ }^{8}$ Icahn School of Medicine at Mount Sinai, New York, NY, USA
} Correspondence: A. Krönke Anna (anna.wischnewski@fau.de) 
Studies suggest that PCBs and $p, p^{\prime}$-DDT disturb the metabolism through hormone receptor interaction ${ }^{7}$ and subsequent changes in histone methylation. ${ }^{8}{ }^{9}$ Resulting changes in the epigenome and transcription rate of certain genes are thought to cause alterations in lipid metabolism and adipogenesis. ${ }^{10}$ Several studies also suggest that $p, p^{\prime}$-DDT and PCBs may impair growth and metabolism through a disturbance of the thyroid gland. ${ }^{11,12}$

The present study aims to identify demographic determinants of serum concentrations of different PCBs and the organochlorine pesticide $p, p^{\prime}$-DDT in pregnant women in Germany, a country that banned the use and production of these POPs in 1991. Furthermore, this study aims to analyse the association between POP serum concentration in mothers at the 24th or 36th week of pregnancy and anthropometric data for their children at birth. With a view, specifically, to identifying the influence-if presentof prenatal exposure to PCBs and DDE on prenatal growth and metabolism, we assessed foetal growth and development using weight, length, and head circumference at birth, and the duration of pregnancy. We additionally analysed weight gain in the first 2 years of life, as fast weight gain in early childhood and low birth weight have been associated with an increased risk of cardiovascular and metabolic disease in adulthood, in line with the Barker hypothesis. ${ }^{13,14}$ In addition, we analysed the influence of maternal PCB and $p, p^{\prime}$-DDE serum levels on thyroid hormone parameters such as thyroid-stimulating hormone (TSH), free triiodothyronine (FT3), and free thyroxine (FT4) both of the mother during pregnancy and of the child at 6 months and at 1 year.

\section{SUBJECTS AND METHODS}

Subjects

The study population consisted of 333 women and their children, who were selected from within the LIFE Child cohort. ${ }^{15}$ LIFE Child is a large, population-based, longitudinal childhood cohort study based in the city of Leipzig in the former East Germany that seeks to monitor healthy child development from birth to adulthood and to offer a more in-depth understanding of the development of lifestyle diseases. The LIFE Child cohort includes mothers born in both the former East Germany and the former West Germany. In the case of pregnant women, assessments were carried out in the 24th and 36th week of pregnancy. Children were assessed at 3, 6, and 12 months of age and once per year thereafter. The mother-child study programme includes age-adapted medical, psychological and sociodemographic assessments and the collection of biological samples.

From our cohort of 333 mothers and their children, nine children and their mothers were excluded due to multiple pregnancies. For 59 out of the remaining 324 women, no data about the children after birth were available. Of the children, $3.5 \%$ $(n=9)$ were born premature (defined as gestational age $<37$ weeks). These children were excluded from all analyses, except those who were involved in the length of pregnancy, resulting in a sample size of 324 mothers and 256 children born following full-term pregnancies. (Fig. 1). In the case of certain models, the sample was reduced further where the necessary data were missing in the "Your child's medical records" or "Maternity Records" booklets (see below), or where data for specific covariates were otherwise unavailable.

The study was designed in accordance with the Declaration of Helsinki. The Ethics committee of the University of Leipzig was involved in the development of the study model and granted its approval for the final design (Reg. No. 264/10-ek). Fully informed, written consent has been obtained from all participants and their parents. $^{15}$

\section{Outcome parameters}

Weight at birth was measured by a midwife directly after birth using a clinical scale. The weight at 1 and 2 years was measured by professional study nurses at the LIFE CHILD study centre using a clinical scale. All anthropometric data, including weight, length and head circumference at birth, were sourced from the booklets "Your child's medical records", which is used throughout Germany to record a child's development, and "Maternity records", which is used to document the course of the pregnancy. To calculate the pre-pregnancy body mass index (BMI), the pre-pregnancy weight and height were taken from the "Maternity records" booklet.

To determine the social status of the participants, an adjusted socioeconomic index as proposed by Winkler and Stolzenberg ${ }^{16}$ was applied. This index is calculated using the parents' education level and occupational status and the net equivalent household 
income, and is expressed in a value between 3 and 21 inclusive, with a score between 3 and 8 indicating low socioeconomic status (SES), a score from 9 to 14 indicating middle SES and values from 15 to 21 was defined as high SES.

We assessed the serum levels of TSH, FT3 and FT4 at 6 months and at 1 year, as well as maternal TSH, FT3 and FT4 serum levels at 24 weeks gestation.

Chemical analysis of the compounds, thyroid hormone parameters and serum lipids

Serum samples were collected between 2011 and 2016 from a pregnant woman in the 24th or 36th week of pregnancy and sent to the National Institute of Health and Welfare laboratory in Kuopio, Finland in February 2016. Results were received in April 2017. Mothers were required to fast for at least $4 \mathrm{~h}$ before blood was drawn. The concentration of 12 POPs, among them ten PCB congeners, $p, p^{\prime}$-DDT and $p, p^{\prime}-\mathrm{DDE}$, was measured, reported in pg/ $\mathrm{ml}$ and subsequently correlated with postnatal outcome parameters in both the mother and child. The specific congeners analysed are summarized in Table 2. The ten PCB congeners exhibited a variety of important characteristics such as coplanar and noncoplanar orientation, different degrees of chlorination and dioxin-like and non-dioxin-like structure, as well as different combinations of chlorine atom positions in the molecule.

Full details of the analysis of the chemical compounds are reported elsewhere. However, to summarize, in the sample preparation of POPs ${ }^{13} \mathrm{C}$-labelled internal standards of each compound were added to the samples. Dichloromethanehexane was used for extraction. Extracts were cleaned with multilayer silica columns. The eluate was concentrated for gas chromatography-tandem mass spectrometry (GC-MS/MS) analysis (Agilent 7010 GC-MS/MS System, Wilmington, DE). ${ }^{17}$ We did not substitute values of compounds below the detection limit to avoid missing weaker signals. ${ }^{18}$

Cotinine, the primary metabolite of nicotine, was measured in the maternal serum in $\mathrm{ng} / \mathrm{ml}$. We used it as a biomarker for smoking during pregnancy, with values $<1 \mathrm{ng} / \mathrm{ml}$ indicating nonsmokers, values between 1 and $10 \mathrm{ng} / \mathrm{ml}$ indicating non-smoking but heavily exposed women and values $>10 \mathrm{ng} / \mathrm{ml}$ indicating active smokers. ${ }^{19}$

Analysis of FT3, FT4 and TSH levels was performed via Elecsys electrochemiluminescence immunoassay using the Cobas modular platform (Roche Diagnostics, Basel, Switzerland) as previously described. ${ }^{20}$

Serum levels of total cholesterol and triglycerides were measured via an enzymatic colour test using the Cobas modular platform (Roche Diagnostics, Basel, Switzerland) as previously described. ${ }^{21}$

\section{Statistics}

First, we examined associations between potential influential factors and the compounds of interest using correlation analysis. Subsequently, in regression models, selected variables that showed a significant association with the dependent variable in bivariate analyses or that have been shown to be influential in former studies were included as covariates in the predictor analysis (Model 1). ${ }^{22-24}$ For the models investigating the association between POPs and the thyroid and growth outcomes, the choice of confounders was based on the construction of a directed acyclic graph. We included maternal nicotine consumption as a covariate in the models for birth weight and postnatal weight gain (Table S1, Model $2 \mathrm{~d}-\mathrm{f}$ ), as we saw a significant association between these variables, in addition to the covariates determined by creating a directed acyclic graph.

Analyses were performed for individual congeners as well as for grouped compounds. The grouping of the compounds was conducted on the basis of the grouping described by Meeker and Hauser. ${ }^{25}$ Compounds were included, according to their postulated mode of action, in one of two groups: ${ }^{25}$ Group 1, potentially anti-oestrogenic and dioxin-like (congeners 74, 118, 138, 156 and 170); Group 2, phenobarbital, CYP1A and CYP2B inducers (congeners 99, 53, 180 and 183).

To analyse the relationship between the pre-partum serum concentration of the compounds and maternal characteristics, robust linear regression modelling ${ }^{26}$ was performed with each compound as a dependent variable and maternal body mass index (BMI), age at conception, serum lipids (sum of total cholesterol and triglycerides) and SES, in turn, as an independent variable (Model 1; Table 3).

Associations between maternal serum concentrations of the compounds and child development parameters including weight, length and head circumference at birth, weight development in the first and second year of life and length of pregnancy were also analysed using robust linear regression modelling. Maternal age and lipid concentration (total cholesterol and triglycerides), prepregnancy BMI and cotinine were considered as potential covariates. Here, we checked for sex differences by adding a respective sex interaction to the model (Model 2, Supplemental Table S1 (online)). Non-significant interaction terms were removed to comply with the principle of parsimony. Due to the statistical approach and small differences between the means and medians of our variables, we did not log transform any variables. The same modelling approach was applied to the relationship between the child serum levels of TSH, FT3 and FT4 at 6 months and 1 year of age, and the maternal compound concentrations using robust linear regression modelling. Maternal serum lipid concentration was used as a covariate (Model 3, Supplemental Table S2 (online)).

Associations between maternal TSH, FT3 and FT4 and compound levels were determined using robust linear regression modelling with serum lipids, BMI and age as covariates (Model 4, Supplemental Table S3 (online)). Furthermore, we used splines to estimate the effective degrees of freedom for all models concerning the thyroid and growth parameters. We also checked if a term of higher order was necessary by modelling the associations with polynomial and compare them to the linear model using analysis of variance. If the higher-order term resulted in a significant model improvement, the results were changed accordingly. Otherwise, the previous result was kept.

We tested for high influence with DFFITS statistic. ${ }^{25}$ Due to the presence of outliers, we chose robust linear regression modelling.

Statistical significance was assumed for all $p<0.05$. R 3.5.2 was used for all data analyses. ${ }^{27}$

\section{RESULTS}

Cohort characteristics

The main characteristics of the cohort are summarized in Table 1. From the 324 included mothers, 23.5\% $(n=76)$ were overweight or obese $\left(B M I>25 \mathrm{~kg} / \mathrm{m}^{2}\right)$ before pregnancy. The mean age at conception was 30.3 years. Of the women, $5.6 \%(n=18)$ were classified as active smokers based on their cotinine measurements; $57.9 \%(n=165)$ of the women were categorized as being of middle SES. Of the women, 3.8\% $(n=12)$ were born in the former West Germany and $53.8 \%(n=169)$ were born in the former East Germany. Ten women were born after German reunification. One hundred and thirty-one women could not be categorized as having been born in East or West Germany. There were slightly more male children (52.7\%) than female children. Of the children, $3.4 \%(n=9)$ were born premature, that is, before a gestational age of 37 weeks.

\section{Concentration and correlation of the compounds in maternal} serum

Measurement of the maternal PCB and $p, p^{\prime}-\mathrm{DDT} / p, p^{\prime}$-DDE serum levels revealed varying levels ranging from $7.91 \mathrm{pg} / \mathrm{ml}$ for PCB 74 
to $128.7 \mathrm{pg} / \mathrm{ml}$ for PCB 153 . The mean serum level for $p, p^{\prime}-\mathrm{DDE}$ was $558.73 \mathrm{pg} / \mathrm{ml}$. For most compounds (excluding $p, p^{\prime}$-DDT and $P C B$ 74), the measured serum concentration was above the certified reference concentration (Table 2). The data for all compounds were right skewed. To visualize the correlations between the maternal concentrations of the different individual compounds, we used a correlation matrix (Fig. 2). As expected, the matrix showed correlations between all compounds, with particularly strong correlations between $p, p^{\prime}$-DDT and $p, p$ '-DDE. Furthermore, we found that the level of correlation between different PCBs was dependent on the degree of chlorination.

\begin{tabular}{|c|c|c|}
\hline & Mean \pm SD & $N=(\%)$ \\
\hline \multicolumn{3}{|l|}{ Maternal characteristics } \\
\hline Age at conception (years) & $30.3 \pm 4.31$ & 324 \\
\hline Pre-pregnancy BMI $\left(\mathrm{kg} / \mathrm{m}^{2}\right)$ & $23.7 \pm 4.69$ & 280 \\
\hline Sociodemographic index score ${ }^{a}$ & & 285 \\
\hline Low social status & & 17 (5.96\%) \\
\hline Middle social status & & $165(57.9 \%)$ \\
\hline High social status & & $103(36.1 \%)$ \\
\hline $\mathrm{TSH}(\mathrm{mU} /)^{\mathrm{b}}$ & $1.83 \pm 1.41$ & 268 \\
\hline $\mathrm{FT} 3(\mathrm{pmol} / \mathrm{l})^{\mathrm{b}}$ & $4.24 \pm 0.51$ & 259 \\
\hline FT4 $(p m o l / l)^{b}$ & $12.66 \pm 2.07$ & 261 \\
\hline \multicolumn{3}{|l|}{ Child characteristics } \\
\hline Sex child & & 256 \\
\hline Male & & $135(52.7 \%)$ \\
\hline Female & & $122(47.7 \%)$ \\
\hline Bodyweight at birth (g) & $3538 \pm 478.78$ & 256 \\
\hline Gain of bodyweight in the first year (\%) & $170 \pm 38.74$ & 203 \\
\hline Body length at birth $(\mathrm{cm})$ & $50.5 \pm 2.41$ & 255 \\
\hline $\mathrm{TSH}(\mathrm{mU} / \mathrm{l})^{\mathrm{d}}$ at 1 year & $3.15 \pm 1.77$ & 93 \\
\hline FT3 $(\mathrm{pmol} / \mathrm{l})^{\mathrm{d}}$ at 1 year & $7.00 \pm 0.82$ & 89 \\
\hline
\end{tabular}

Demographic determinants of POP levels and associations between POPs and child characteristics

Our first aim was to investigate demographic determinants for serum levels of the various POPs measured. Therefore, we created a robust linear regression model with the compounds as a dependent variable and maternal age, BMI, SES and serum lipids as independent covariables. We found significant positive associations between maternal age and serum concentrations for $p, p^{\prime}-\mathrm{DDE}$ and all PCBs, except PCB 74. Conversely, we observed a negative association between maternal pre-pregnancy $\mathrm{BMI}$ and serum concentrations of a subset of PCBs (Table 3 ). Figure 3 shows the association between BMI and the various POPs in the form of predicted compound serum concentrations for a rising maternal BMI. There were no significant associations between categories of SES and serum levels of $p, p^{\prime}$-DDE or the different PCBs. All measured compounds were positively associated with serum lipid concentrations in the mother.

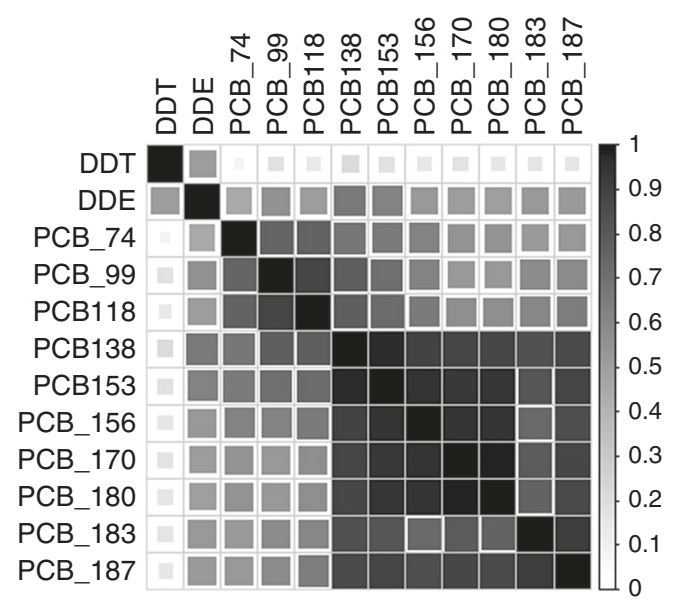

Fig. 2 Visualized correlation matrix of the PCB, $p, p^{\prime}-D D T$ and $p, p^{\prime}-$ DDE serum levels. Correlation matrix with darker shades of grey indicating stronger positive correlations between the compounds. PCB polychlorinated biphenyls, DDT dichlorodiphenyltrichlorethane, DDE dichlorodiphenyldichloroethylene.

Table 2. Concentrations of compounds of interest in maternal serum (pg/ml), N=324.

\begin{tabular}{|c|c|c|c|c|}
\hline PCB 74 & $7.91 \pm 4.49$ & 6.41 & 66.05 & 4 \\
\hline PCB 99 & $10.01 \pm 5.51$ & 8.77 & 84.26 & 5 \\
\hline PCB 138 & $81.66 \pm 42.33$ & 75.08 & 100 & 6 \\
\hline PCB 153 & $128.70 \pm 69.01$ & 115.69 & 100 & 6 \\
\hline PCB 180 & $82.85 \pm 49.16$ & 71.27 & 89 & 7 \\
\hline PCB 183 & $12.00 \pm 6.96$ & 10.52 & 89.51 & 7 \\
\hline PCB 187 & $19.62 \pm 12.58$ & 16.31 & 97.53 & 7 \\
\hline$p, p^{\prime}$-DDT & $23.01 \pm 24.56$ & 15.00 & 29 & \\
\hline$p, p^{\prime}-\mathrm{DDE}$ & $558.73 \pm 439.62$ & 417.63 & 100 & \\
\hline
\end{tabular}


Table 3. Results from robust linear regression models for $P C B$ and $p, p^{\prime}$-DDE maternal serum concentrations $(N=246)$.

\begin{tabular}{|c|c|c|c|c|}
\hline Dependent variable & Independent variable & Beta & Std. error & $\operatorname{Pr}(>|t|)$ \\
\hline \multirow[t]{4}{*}{ DDE } & Age & 11.599 & 4.348 & 0.008 \\
\hline & SES & 6.230 & 6.412 & 0.332 \\
\hline & BMI & 0.031 & 3.477 & 0.993 \\
\hline & Serum lipids & 23.995 & 8.987 & 0.008 \\
\hline \multirow[t]{4}{*}{ PCB 74} & Age & 0.071 & 0.047 & 0.129 \\
\hline & SES & 0.037 & 0.064 & 0.564 \\
\hline & BMI & -0.024 & 0.034 & 0.481 \\
\hline & Serum lipids & 0.302 & 0.098 & 0.002 \\
\hline \multirow[t]{4}{*}{ РCB 99} & Age & 0.158 & 0.069 & 0.024 \\
\hline & SES & 0.120 & 0.101 & 0.237 \\
\hline & BMI & -0.057 & 0.055 & 0.295 \\
\hline & Serum lipids & 0.607 & 0.151 & $<0.0001$ \\
\hline \multirow[t]{4}{*}{ PCB 118} & Age & 0.696 & 0.173 & $<0.0001$ \\
\hline & SES & 0.480 & 0.263 & 0.070 \\
\hline & BMl & -0.073 & 0.144 & 0.613 \\
\hline & Serum lipids & 1.896 & 0.383 & $<0.0001$ \\
\hline \multirow[t]{4}{*}{ PCB 138} & Age & 2.649 & 0.546 & $<0.0001$ \\
\hline & SES & 0.702 & 0.799 & 0.381 \\
\hline & BMl & -0.691 & 0.434 & 0.113 \\
\hline & Serum lipids & 7.101 & 1.141 & $<0.0001$ \\
\hline \multirow[t]{4}{*}{ PCB 153} & Age & 5.362 & 0.811 & $<0.0001$ \\
\hline & SES & 0.931 & 1.192 & 0.435 \\
\hline & BMI & -1.828 & 0.643 & 0.005 \\
\hline & Serum lipids & 10.632 & 1.689 & $<0.0001$ \\
\hline \multirow[t]{4}{*}{ PCB 156} & Age & 0.580 & 0.089 & $<0.0001$ \\
\hline & SES & 0.087 & 0.131 & 0.505 \\
\hline & BMI & -0.234 & 0.071 & 0.001 \\
\hline & Serum lipids & 1.170 & 0.184 & $<0.0001$ \\
\hline \multirow[t]{4}{*}{ PCB 170} & Age & 2.307 & 0.290 & $<0.0001$ \\
\hline & SES & 0.122 & 0.417 & 0.771 \\
\hline & $\mathrm{BMI}$ & -0.818 & 0.223 & 0.0003 \\
\hline & Serum lipids & 3.811 & 0.591 & $<0.0001$ \\
\hline \multirow[t]{4}{*}{ PCB 180} & Age & 4.751 & 0.508 & $<0.0001$ \\
\hline & SES & 0.242 & 0.727 & 0.739 \\
\hline & BMI & -1.745 & 0.391 & $<0.0001$ \\
\hline & Serum lipids & 6.444 & 1.029 & $<0.0001$ \\
\hline \multirow[t]{4}{*}{ РCB 183} & Age & 0.477 & 0.099 & $<0.0001$ \\
\hline & SES & 0.117 & 0.146 & 0.421 \\
\hline & BMl & -0.108 & 0.078 & 0.167 \\
\hline & Serum lipids & 0.912 & 0.213 & $<0.0001$ \\
\hline \multirow[t]{4}{*}{ PCB 187} & Age & 0.966 & 0.160 & $<0.0001$ \\
\hline & SES & 0.049 & 0.237 & 0.837 \\
\hline & BMI & -0.298 & 0.126 & 0.019 \\
\hline & Serum lipids & 1.227 & 0.349 & 0.0005 \\
\hline
\end{tabular}

The multivariate regression models revealed consistently negative associations between the compounds and maternal $\mathrm{BMI}$, which reached the level of significance for PCB 153,156, 170,180 and 187. There were also consistently positive associations between the compounds and maternal age and maternal serum lipid levels. In this model, we included the compounds of interest as a dependent variable and maternal age, $\mathrm{BMI}$, socioeconomic status and serum lipids as covariates.

Serum lipids as the sum of total serum cholesterol and serum triglycerides in $\mathrm{mmol} / \mathrm{l}$, SES socioeconomic status of participants determined using the adjusted socioeconomic index as set out by Winkler, $\operatorname{Pr}(>|t|) p$ value for the $t$ test, Std. error standard error, $P C B$ polychlorinated biphenyl, $D D E$ dichlorodiphenyldichloroethylene.
Next, we analysed associations between maternal PCB and $p, p^{\prime}-$ DDE serum levels and child characteristics (Supplemental Table S1 (online)). Maternal levels of $p, p^{\prime}-\mathrm{DDE}$ and PCBs showed no statistically significant association with the parameters of child weight $(\mathrm{g})$ and head circumference $(\mathrm{cm})$ at birth or with the duration of pregnancy (days). However, we found a significant negative association between the concentration of PCB 183 and length at birth $(\mathrm{cm})$. In addition, concentrations of maternal serum $p, p^{\prime}$-DDE and several PCBs (PCB 99, 118,138, 153, 156, 170, 180 and PCB Groups 1 and 2) positively correlated with weight gain in the first 2 years of life (\%). Concentrations of PCB Group 1, which are known to exhibit potentially anti-oestrogenic and dioxin-like "effects", were also associated with weight gain within the first year of life (Supplemental Table S1 (online)). An analysis of weight gain in the children over the first 2 years of life showed that the weight gained in the children of mothers from the 90th percentile of PCB Group 1 serum concentrations equated to $113 \%$ of that gained by children of mothers from the 10th percentile (Table 4).

We adjusted for maternal age, BMI and serum lipids in the models analysing the maternal thyroid parameters, whereas adjustment for maternal serum lipids was performed in the models analysing the child's thyroid parameters. Here, we identified significant associations between maternal POP levels and thyroid hormone parameters in both mother and child. Among these, concentrations of maternal PCB 99 and 183 were positively associated with the child's thyroid hormone parameter FT3 at the age of 6 months for girls only. The mean FT3 level at age 6 months for girls was $6.8 \%$ higher in the children of mothers in the 90th percentile for serum concentrations of PCB 99 compared to children of mothers in the 10th percentile (Table 5). Maternal $p, p^{\prime}$-DDE concentrations were negatively associated with FT3 serum concentrations of male children at age 1 year. Maternal $p, p^{\prime}-\mathrm{DDE}$, all measured PCB serum concentrations, except PCB 156, and both compound groupings negatively correlated with serum FT3 levels in the mothers. The mean FT3 concentration in mothers in the 90th percentile for $p, p^{\prime}$-DDE serum concentration was $8.1 \%$ lower than in mothers in the 10th percentile (Table 6). Table 6 shows the estimates for maternal FT3 for the 10th, 50th and 90th percentile for levels of all congeners. There was an additional negative correlation between maternal serum $p, p^{\prime}-\mathrm{DDE}, \mathrm{PCB} 74$ and 118 concentration and maternal TSH (Supplemental Table S3 (online)). In line with that, we found a negative correlation between maternal serum PCB 99 and 118 and the child's TSH levels.

\section{DISCUSSION}

Although the exact threshold for the endocrine modulatory action of POPs remains unclear, it has been shown that PCBs and $p, p^{\prime}$-DDE are able to cross the placental barrier. ${ }^{28}$ The high percentage of $\mathrm{PCB}$ and $p, p^{\prime}-\mathrm{DDE}$ concentrations above the certified reference concentration in maternal sera from our cohort strongly suggests that both the mothers and their unborn children were exposed to potentially harmful concentrations of POPs, and that our study is, therefore, useful in determining potential adverse effects of POPs.

Regarding the demographic characteristics that could potentially influence the maternal serum concentration of POPs, we found age and maternal BMI to be the most influential. Here, we observed significant associations between age and all tested compounds, except PCB 74, and between BMI and PCB 153, 156, 170,180 and 187 . This finding is likely attributable to the rise in lipophilicity-induced accumulation in human adipose tissue as the degree of chlorination increases. Both findings are in line with a previous study. ${ }^{29}$

Another major finding of our study was significant positive associations between maternal POP levels and postnatal weight development, with a significant association between specific PCBs 

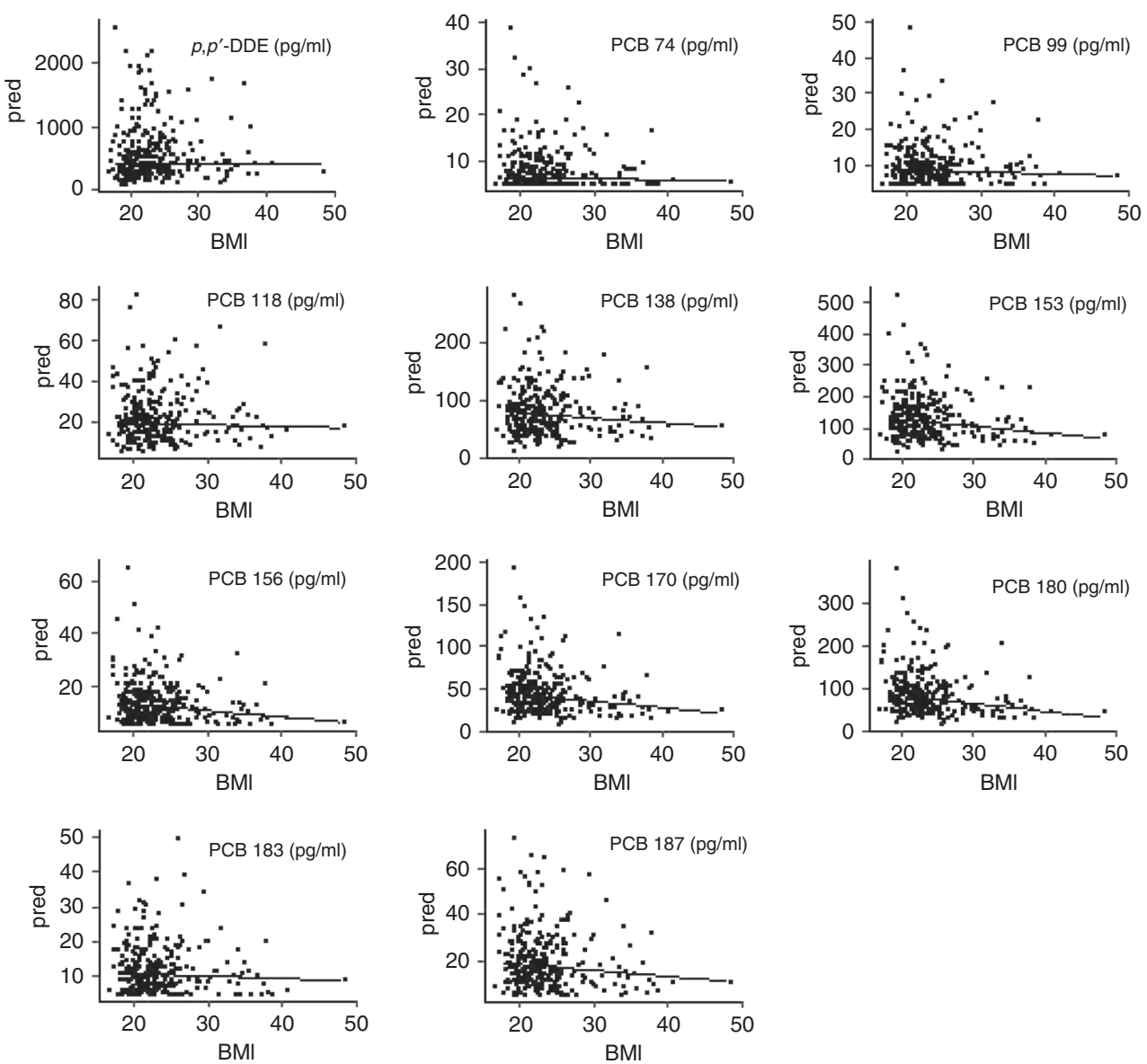

Fig. 3 Association between maternal BMI and compound serum concentration. The underlying model for the graph is a robust linear regression model with the individual compound as a dependent variable and maternal age, BMl and socioeconomic score as independent variables. The graphs show the predicted value for the concentration of the compound given a set age and socioeconomic status, while BMI rises in discrete steps between 18 and 48.

$\left(99,118,138,153,156,170,180\right.$, Group 1, Group 2) and $p, p^{\prime}-\mathrm{DDE}$ and child weight gain. PCB effects on weight have been reported in multiple prior studies as ranging from no effect to positive or even negative correlations. ${ }^{30,} 31$ While the reasons for these varying results remain elusive, the mechanisms through which PCBs might affect weight gain are presumably a combination of effects on the action of thyroid hormones, ${ }^{32}$ oestrogen-related receptor $\gamma^{33}$ and glucose homeostasis, ${ }^{34}$ all factors that critically influence postnatal development. As weight gain within the first 2 years of life is known to be linked to metabolic alterations in adulthood, these findings suggest a potential influence of prenatal POP exposure on the development of metabolic diseases such as type 2 diabetes later in life.

Other anthropometric parameters for the children in our cohort, including weight and head circumference at birth, were not associated with maternal POP levels with the exception of PCB 183 , which was negatively associated with the child's length at birth. These findings only partially support the results of the Spanish INMA (INfancio y Medio Ambiente) cohort, which showed a significant reduction of foetal femur length from week 20 onward in individuals exposed to higher PCB levels. ${ }^{35}$ Other studies did not confirm a significant association between PCBs and length at birth. ${ }^{36}$

Our study additionally revealed a potential impact of POPs on the thyroid hormone status in mothers and their children. We found a negative correlation between $p, p^{\prime}$-DDE and all PCB levels, except $P C B$ 156, and FT3 levels in mothers, and a negative correlation between $p, p^{\prime}-\mathrm{DDE}, \mathrm{PCB} 74$ and 118 exposure and maternal TSH levels. Moreover, we detected a positive association between maternal PCB 99 and 183 and FT3 in the respective female children at an age of 6 months, whereas we found a negative association between $p, p^{\prime}$-DDE and FT3 serum levels in boys at an age of 1 year. The inverse association between PCBs and FT3 serum levels in maternal blood has been reported on more than one occasion in prior research, 37,38 although other studies report different results, ${ }^{39}$ with no association or even positive correlations between POP levels and thyroid hormone parameters. ${ }^{25}$ These discrepancies might be due to differences in the size or sex distribution of the study cohorts, concentration ranges of the POPs investigated or differences in the covariables used. Takser et al., ${ }^{38}$ who also observed a negative association between maternal serum levels for PCB 138, 153 and 180 and maternal T3 serum levels, found no significant association between maternal PCB exposure and the child's thyroid hormone levels. The difference in PCB serum concentration, which was twice as high in our cohort, might be responsible for the discrepancy in these findings. Wilhelm et al. ${ }^{39}$ similarly found no impairment of the thyroid function of infants, although the PCB concentrations they measured were three times higher, which leads to the assumption that the discrepancy in the findings cannot solely be explained by differences in the compound concentrations. Although this variance in findings has not yet been fully explained, and may be due to as yet unidentified factors, the influence of certain PCBs and $p, p^{\prime}$-DDE on the thyroid hormone system seems likely. The underlying mechanisms of the potential influence of POPs on FT3 and TSH levels might include 
Table 4. Estimates for the weight gain of the child in the first 2 years of life (\%) for the 10th, 50th and 90th percentile of maternal serum compound concentration.

\begin{tabular}{llll}
\hline $\begin{array}{l}\text { Independent } \\
\text { variable }\end{array}$ & \multicolumn{3}{l}{$\begin{array}{l}\text { Weight gain of child in the first } 2 \text { years of life (\%) } \\
\text { for the }\end{array}$} \\
\cline { 2 - 4 } & $\begin{array}{l}\text { 10th compound } \\
\text { percentile }\end{array}$ & $\begin{array}{l}\text { 50th compound } \\
\text { percentile }\end{array}$ & $\begin{array}{l}\text { 90th compound } \\
\text { percentile }\end{array}$ \\
\hline DDE & 246.264 & 250.530 & 264.705 \\
PCB 74 & 251.391 & 252.585 & 258.718 \\
PCB 99 & 240.943 & 251.263 & 271.646 \\
PCB 118 & 242.247 & 251.641 & 270.086 \\
PCB 138 & 239.655 & 251.639 & 273.080 \\
PCB 153 & 241.322 & 251.720 & 271.057 \\
PCB 156 & 242.808 & 251.897 & 270.864 \\
PCB 170 & 242.596 & 251.732 & 270.023 \\
PCB 180 & 244.247 & 251.590 & 269.274 \\
PCB 183 & 242.654 & 252.322 & 270.402 \\
PCB 187 & 244.326 & 252.066 & 268.839 \\
PCB Group 1 & 240.094 & 251.498 & 271.439 \\
PCB Group 2 & 241.918 & 251.464 & 270.269 \\
\hline
\end{tabular}

Robust linear regression models with the child's weight gain in the first 2 years of life (\%) as a dependent variable and the respective compound of interest as an independent variable reveals higher weight gain for higher compound concentrations. Analyses were adjusted for maternal age maternal $\mathrm{BMI}$, maternal nicotine consumption and maternal serum lipid concentrations.

The underlying model reached the level of significance for DDE, PCB 99, $118,138,153,156,170,180$ and both PCB groups.

Weight gain in the first 2 years of life $(\%)=$ (weight at 2 years $(\mathrm{g})$ - weight at birth $(\mathrm{g})) /$ weight at birth $(\mathrm{g}) \times 100$.

$P C B$ polychlorinated biphenyl, $D D E$ dichlorodiphenyldichloroethylene.

${ }^{a}$ Group 1: sum of potentially antiestrogenic and dioxin-like PCB congeners $(74+118+138+156+170)$.

${ }^{\mathrm{b}}$ Group 2: sum of phenobarbital, CYP1A and CYP2B inducing PCB congeners $(99+153+180+183)$

an increase in the hepatic metabolism of thyroid hormones resulting from exposure of the liver to POP compounds. ${ }^{40}$ However, this would not explain the observed decrease in maternal TSH. Another possible explanation is therefore a potential direct effect on the action of thyroid hormones via interaction with the thyroid hormone receptor, which might trigger a negative feedback in the pituitary gland, resulting in a decrease in TSH and a consequent decrease in FT3. ${ }^{25}$

One strength of our study is the simultaneous availability of blood samples from mothers and their children, as well as the wide range of measured child characteristics. These could potentially be used for a follow-up study looking at the impact of PCBs and $p, p^{\prime}$-DDE on development later in life. The limitations include the relatively small sample size and the isolated analysis of individual compounds, compared with other studies, which focused on compound mixtures. Other limitations include the relatively small effect sizes, which, in combination with multiple comparisons, increases the risk of type one error. In concert with related studies, however, the observed effects contribute to a better understanding of the potential mode of action of POPs and their harmful effects in humans. The significant associations between the analysed compounds and certain parameters of child development and thyroid hormone status support the assertion that further research is needed on the potentially harmful action of PCBs and $p, p^{\prime}-\mathrm{DDT} / p, p^{\prime}-\mathrm{DDE}$.
Table 5. Estimates for the FT3 serum concentration in the child at age 6 months for the 10th, 50th and 90th percentile of maternal serum compound concentration.

\begin{tabular}{|c|c|c|c|}
\hline \multirow[t]{2}{*}{$\begin{array}{l}\text { Independent } \\
\text { variable }\end{array}$} & \multicolumn{3}{|c|}{$\begin{array}{l}\text { Child FT3 serum concentration at age } 6 \text { months } \\
\text { (pmol/l) for the }\end{array}$} \\
\hline & $\begin{array}{l}\text { 10th compound } \\
\text { percentile }\end{array}$ & $\begin{array}{l}\text { 50th compound } \\
\text { percentile }\end{array}$ & $\begin{array}{l}\text { 90th compound } \\
\text { percentile }\end{array}$ \\
\hline DDE female & 6.814 & 6.762 & 6.783 \\
\hline DDE male & 7.216 & 7.123 & 6.959 \\
\hline PCB 74 female & 6.822 & 6.845 & 6.766 \\
\hline PCB 74 male & 7.172 & 7.424 & 6.962 \\
\hline PCB 99 female & 6.489 & 6.802 & 7.049 \\
\hline PCB 99 male & 7.278 & 7.10 & 6.912 \\
\hline PCB 118 female & 6.812 & 6.822 & 6.747 \\
\hline PCB 118 male & 7.188 & 7.093 & 7.063 \\
\hline PCB 138 female & 6.490 & 6.820 & 7.004 \\
\hline PCB 138 male & 7.329 & 7.101 & 6.871 \\
\hline PCB 153 female & 6.512 & 6.804 & 7.014 \\
\hline PCB 153 male & 7.335 & 7.111 & 6.843 \\
\hline PCB 156 female & 6.655 & 6.771 & 6.915 \\
\hline PCB 156 male & 7.321 & 7.117 & 6.824 \\
\hline PCB 170 female & 6.659 & 6.752 & 6.897 \\
\hline PCB 170 male & 7.336 & 7.121 & 6.830 \\
\hline PCB 180 female & 6.669 & 6.767 & 6.911 \\
\hline PCB 180 male & 7.329 & 7.137 & 6.823 \\
\hline PCB $183^{a}$ female & 6.375 & 6.845 & 7.095 \\
\hline PCB $183^{a}$ male & 7.354 & 7.087 & 6.847 \\
\hline PCB 187 female & 6.737 & 6.778 & 6.841 \\
\hline PCB 187 male & 7.287 & 7.127 & 6.913 \\
\hline $\begin{array}{l}\text { PCB Group } \\
1^{\mathrm{b}} \text { female }\end{array}$ & 6.538 & 6.802 & 6.975 \\
\hline $\begin{array}{l}\text { PCB Group } \\
1^{\mathrm{b}} \text { male }\end{array}$ & 7.317 & 7.112 & 6.889 \\
\hline $\begin{array}{l}\text { PCB Group } 2^{c} \\
\text { female }\end{array}$ & 6.531 & 6.790 & 7.009 \\
\hline $\begin{array}{l}\text { PCB Group } \\
2^{C} \text { male }\end{array}$ & 7.335 & 7.113 & 6.845 \\
\hline
\end{tabular}

Robust linear regression models with the FT3 serum concentration in the child at age 6 months as a dependent variable and the respective compound of interest as independent variables reveal lower FT3 concentrations for higher compound concentrations. Analyses were adjusted for maternal serum lipid concentration and an interaction term for the sex of the child was included.

The underlying model reached the level of significance for PCB 99 for females and for PCB 183 for females.

$P C B$ polychlorinated biphenyl, $D D E$ dichlorodiphenyldichloroethylene, FT3 free triiodothyronine $(\mathrm{pmol} / \mathrm{l})$.

${ }^{\mathrm{a}}$ For PCB 183, a polynomial of second order with FT3 serum concentration of the child at age 6 months as dependent variable reveals significant higher FT3 serum concentrations for girls of mothers with higher compound serum concentrations. We checked if a term of higher order was necessary by modelling the associations with polynomial and compare them to the linear model using analysis of variance. If the higher-order term resulted in a significant model improvement, the results were changed accordingly.

${ }^{\mathrm{b}}$ Group 1: sum of potentially antiestrogenic and dioxin-like PCB congeners $(74+118+138+156+170)$.

'Group 2: sum of phenobarbital, CYP1A and CYP2B inducing PCB congeners $(99+153+180+183)$. 
Persistent organic pollutants in pregnant women potentially affect child... AA Krönke et al.

Table 6. Estimates of maternal FT3 serum concentration for the 10th, 50th and 90th percentile of maternal serum compound concentration.

Independent Maternal FT3 serum concentration (pmol/l) for the variable

\begin{tabular}{|c|c|c|c|}
\hline & $\begin{array}{l}\text { 10th compound } \\
\text { percentile }\end{array}$ & $\begin{array}{l}\text { 50th compound } \\
\text { percentile }\end{array}$ & $\begin{array}{l}\text { 90th compound } \\
\text { percentile }\end{array}$ \\
\hline $\mathrm{DDE}^{\mathrm{a}}$ & 4.361 & 4.240 & 4.033 \\
\hline PCB 74 & 4.283 & 4.260 & 4.144 \\
\hline РCB 99 & 4.286 & 4.242 & 4.156 \\
\hline PCB 118 & 4.328 & 4.251 & 4.10 \\
\hline PCB 138 & 4.353 & 4.251 & 4.069 \\
\hline PCB 153 & 4.349 & 4.249 & 4.066 \\
\hline PCB 156 & 4.307 & 4.239 & 4.098 \\
\hline PCB 170 & 4.311 & 4.241 & 4.102 \\
\hline PCB $180^{\mathrm{a}}$ & 4.374 & 4.227 & 4.021 \\
\hline PCB 183 & 4.370 & 4.257 & 4.046 \\
\hline PCB 187 & 4.353 & 4.258 & 4.053 \\
\hline PCB Group $1^{\mathrm{b}}$ & 4.355 & 4.251 & 4.071 \\
\hline PCB Group $2^{C}$ & 4.340 & 4.251 & 4.075 \\
\hline
\end{tabular}

Robust linear regression models with the maternal FT3 serum concentration as a dependent variable and the respective compound of interest as independent variables reveal lower FT3 concentrations for higher compound concentrations. Analyses were adjusted for maternal age, maternal BMI and maternal serum lipid concentration.

The underlying model reached the level of significance for all compounds and both PCB groups, except PCB 156.

$P C B$ polychlorinated biphenyl, DDE dichlorodiphenyldichloroethylene, FT3 free triiodothyronine $(\mathrm{pmol} / \mathrm{l})$.

${ }^{\mathrm{a}}$ For DDE and PCB 180, a polynomial of second order with FT3 serum concentration as a dependent variable reveals significant higher FT3 serum concentrations for women with higher compound serum concentrations. We checked if a term of higher order was necessary by modelling the associations with polynomial and compare them to the linear model using analysis of variance. If the higher-order term resulted in a significant model improvement, the results were changed accordingly. Otherwise, the previous result was kept.

${ }^{\mathrm{b}}$ Group 1: sum of potentially antiestrogenic and dioxin-like PCB congeners $(74+118+138+156+170)$.

'Group 2: sum of phenobarbital, $C Y P 1 A$ and $C Y P 2 B$ inducing $P C B$ congeners $(99+153+180+183)$.

\section{ACKNOWLEDGEMENTS}

We thank the mothers and their children for participating in this study, as well as the whole LIFE Child study team. This publication is supported by LIFE-Leipzig Research Center for Civilization Diseases, University of Leipzig. LIFE receives funding from the European Union, through the European Social Fund (ESF) and the European Regional Development Fund (ERDF), from the Free State of Saxony within the framework of the excellence initiative. A.H. is supported by the German Federal Ministry of Education and Research (Grant 01EO1501). This study was performed as part of the EU project EDC-MixRisk.

\section{AUTHOR CONTRIBUTIONS}

Conception and design: W.K., A.A.K. and M.N. Acquisition of data: A.J. and H.K. Analysis and interpretation of data: A.A.K. and M.V. Drafting the article: A.A.K. Revising the article critically for important intellectual content: A.J., M.S., T.P., M.N., A.H., A.K., H. K., M.V., O.S., C.G.B. and W.K. Final approval: C.G.B., O.S., H.K. and W.K.

\section{FUNDING}

Open Access funding enabled and organized by Projekt DEAL.

\section{ADDITIONAL INFORMATION}

Supplementary information The online version contains supplementary material available at https://doi.org/10.1038/s41390-021-01488-5.

Competing interests: The authors declare no competing interests.

Statement of consent: Fully informed, written consent has been obtained from all participants and their parents.

Publisher's note Springer Nature remains neutral with regard to jurisdictional claims in published maps and institutional affiliations.

\section{REFERENCES}

1. Beyer, A. \& Biziuk, M. Environmental fate and global distribution of polychlorinated biphenyls. Rev. Environ. Contam. Toxicol. 201, 137-158 (2009).

2. Weber, R. et al. Life cycle of PCBs and contamination of the environment and of food products from animal origin. Environ. Sci. Pollut. Res. 25, 16325-16343 (2018).

3. UNEP. Stockholm Conventions on Persistent Organic Pollutants (POPs) Texts and Annexes (UNEP, 2017).

4. International Programme on Chemical Safety. Global Assessment on the State of the Science of Endocrine Disruptors (World Health Organization, 2002).

5. Bergman, Å., Heindel, J., Jobling, S., Kidd, K. \& Zoeller, R. T. State-of-the-science of endocrine disrupting chemicals, 2012. Toxicol. Lett. 211, S3 (2012).

6. Hoffmann, M. et al. Endocrine disruptors: Evidence from epidemiological studies necessitates a critical review of model systems. Bundesgesundheitsblatt Gesundheitsforschung Gesundheitsschutz https://doi.org/10.1007/s00103-017-2551-8 (2017).

7. Portigal, C. L. et al. Polychlorinated biphenyls interfere with androgen-induced transcriptional activation and hormone binding. Toxicol. Appl. Pharmacol. 179, 185-194 (2002)

8. Casati, L., Sendra, R., Poletti, A., Negri-Cesi, P. \& Celotti, F. Androgen receptor activation by polychlorinated biphenyls. Epigenetics 8, 1061-1068 (2013).

9. Casati, L. et al. Polychlorinated biphenyls affect histone modification pattern in early development of rats: a role for androgen receptor-dependent modulation? Epigenomics 4, 101-112 (2012).

10. Foulds, C. E., Treviño, L. S., York, B. \& Walker, C. L. Endocrine-disrupting chemicals and fatty liver disease. Nat. Rev. Endocrinol. 13, 445-457 (2017).

11. Meeker, J. D. \& Hauser, R. Exposure to polychlorinated biphenyls (PCBs) and male reproduction. Syst. Biol. Reprod. Med. 56, 122-131 (2010).

12. Yaglova, N. V. \& Yaglov, V. V. Cytophysiological changes in the follicular epithelium of the thyroid gland after long-term exposure to low doses of dichlorodiphenyltrichloroethane (DDT). Bull. Exp. Biol. Med. 162, 699-702 (2017).

13. Lule, S. A. et al. Are birthweight and postnatal weight gain in childhood associated with blood pressure in early adolescence? Results from a Ugandan birth cohort. Int. J. Epidemiol. 48, 148-156 (2019).

14. Barker, D. J. The fetal and infant origins of adult disease. BMJ 301, 1111 (1990).

15. Poulain, T. et al. The LIFE Child study: a population-based perinatal and pediatric cohort in Germany. Eur. J. Epidemiol. 32, 145-158 (2017).

16. Winkler, J. \& Stolzenberg, H. Adjustierung des Sozialen-Schicht-Index für die Anwendung im Kinder-und Jugendgesundheitssurvey (KiGGS). http://www. econstor.eu/handle/10419/39197 (2009).

17. Koponen, J., Rantakokko, P., Airaksinen, R. \& Kiviranta, H. Determination of selected perfluorinated alkyl acids and persistent organic pollutants from a small volume human serum sample relevant for epidemiological studies. J. Chromatogr. A 1309, 48-55 (2013).

18. Needham, L. L. \& Wang, R. Y. Analytic considerations for measuring environmental chemicals in breast milk. Environ. Health Perspect. 110, A317-A324 (2002).

19. Hukkanen, J., Jacob, P. \& Benowitz, N. L. Metabolism and disposition kinetics of nicotine. Pharmacol. Rev. 57, 79-115 (2005).

20. Kronenberg, H. M. et al. Williams Textbook of Endocrinology 12th edn, Ch. 10, 301-311 (Saunders, Elsevier, 2011).

21. Greiling, H. \& Gressner A. M. (eds). Lehrbuch der Klinischen Chemie und Pathobiochemie 3rd edn (Schattauer, 1995).

22. Arrebola, J. P., Cuellar, M., Bonde, J. P., González-Alzaga, B. \& Mercado, L. A. Associations of maternal o, $\mathrm{p}^{\prime}$-DDT and p, $\mathrm{p}^{\prime}$-DDE levels with birth outcomes in a Bolivian cohort. Environ. Res. 151, 469-477 (2016).

23. González-Alzaga, B. et al. Serum concentrations of organochlorine compounds and predictors of exposure in children living in agricultural communities from South-Eastern Spain. Environ. Pollut. 237, 685-694 (2018).

24. Ballon, M. et al. Which modifiable prenatal factors mediate the relation between socio-economic position and a child's weight and length at birth? Matern. Child Nutr. 15, e12878 (2019). 
25. Meeker, J. D., Altshul, L. \& Hauser, R. Serum PCBs, p,p'-DDE and HCB predict thyroid hormone levels in men. Environ. Res. 104, 296-304 (2007).

26. Marazzi, A. Algorithms, Routines and S Functions for Robust Statistics (Wadsworth \& Brooks/Cole, 1993).

27. R Core Team. R: A Language and Environment for Statistical Computing (R Foundation for Statistical Computing, 2019).

28. Junqué, E. et al. Changes of organochlorine compound concentrations in maternal serum during pregnancy and comparison to serum cord blood composition. Environ. Res. 182, 108994 (2020).

29. Bjerregaard-Olesen, C. et al. Temporal trends of lipophilic persistent organic pollutants in serum from Danish nulliparous pregnant women 2011-2013. Environ. Sci. Pollut. Res. 24, 16592-16603 (2017).

30. Tang-Péronard, J. L., Andersen, H. R., Jensen, T. K. \& Heitmann, B. L. Endocrinedisrupting chemicals and obesity development in humans: a review. Obes. Rev. 12, 622-636 (2011).

31. Iszatt, N. et al. Prenatal and postnatal exposure to persistent organic pollutants and infant growth: a pooled analysis of seven European Birth Cohorts. Environ. Health Perspect. 123, 730-736 (2015).

32. Shields, B. M., Knight, B. A., Hill, A., Hattersley, A. T. \& Vaidya, B. Fetal thyroid hormone level at birth is associated with fetal growth. J. Clin. Endocrinol. Metab. 96, E934-E938 (2011).

33. Cao, L.-Y., Ren, X.-M. \& Guo, L.-H. Estrogen-related receptor $\gamma$ is a novel target for lower-chlorinated polychlorinated biphenyls and their hydroxylated and sulfated metabolites. Environ. Pollut. 254, 113088 (2019).

34. Baker Nicki, A. et al. Effects of adipocyte aryl hydrocarbon receptor deficiency on PCB-induced disruption of glucose homeostasis in lean and obese mice. Environ. Health Perspect. 123, 944-950 (2015).

35. Lopez-Espinosa, M.-J. et al. Organochlorine compounds and ultrasound measurements of fetal growth in the INMA cohort (Spain). Environ. Health Perspect. 124, 157-163 (2016).
36. Patel, J. F., Hartman, T. J., Sjodin, A., Northstone, K. \& Taylor, E. V. Prenatal exposure to polychlorinated biphenyls and fetal growth in British girls. Environ. Int. 116, 116-121 (2018)

37. Alvarez-Pedrerol, M. et al. Organochlorine compounds, iodine intake, and thyroid hormone levels during pregnancy. Environ. Sci. Technol. 43, 7909-7915 (2009).

38. Takser, L. et al. Thyroid hormones in pregnancy in relation to environmental exposure to organochlorine compounds and mercury. Environ. Health Perspect. 113, 1039-1045 (2005).

39. Wilhelm, M. et al. The Duisburg birth cohort study: influence of the prenatal exposure to PCDD/Fs and dioxin-like PCBs on thyroid hormone status in newborns and neurodevelopment of infants until the age of 24 months. Mutat. Res. 659, 83-92 (2008).

40. Qatanani, M., Zhang, J. \& Moore, D. D. Role of the constitutive androstane receptor in xenobiotic-induced thyroid hormone metabolism. Endocrinology 146, 995-1002 (2005).

Open Access This article is licensed under a Creative Commons Attribution 4.0 International License, which permits use, sharing, adaptation, distribution and reproduction in any medium or format, as long as you give appropriate credit to the original author(s) and the source, provide a link to the Creative Commons license, and indicate if changes were made. The images or other third party material in this article are included in the article's Creative Commons license, unless indicated otherwise in a credit line to the material. If material is not included in the article's Creative Commons license and your intended use is not permitted by statutory regulation or exceeds the permitted use, you will need to obtain permission directly from the copyright holder. To view a copy of this license, visit http://creativecommons. org/licenses/by/4.0/.

(c) The Author(s) 2021 